\title{
Há territorialidade na pesca artesanal da Baía de Ubatumirim (Ubatuba, SP)? Questões intra, inter e extra-comunitárias
}

\author{
Célia Regina Tomiko Futemma ${ }^{1 *}$ \\ Cristiana Simão Seixas ${ }^{2}$ \\ ${ }^{1}$ Universidade Federal de São Carlos, Campus de Sorocaba \\ Caixa Postal 3031, CEP 18043-970, Sorocaba - SP, Brasil \\ ${ }^{2}$ Fisheries and Food Institute, Campinas - SP, Brasil \\ *Autor para correspondência \\ cfutemma@ufscar.br
}

Submetido em 10/09/2007

Aceito para publicação em 12/11/2007

\section{Resumo}

A questão de escala é fundamental para se analisar as dimensões temporal e institucional da territorialidade pesqueira. Para entender as ações e decisões locais e regionais da pesca, estudamos as comunidades pesqueiras da Baía de Ubatumirim, com ênfase particular na comunidade da Almada, todas localizadas no litoral norte do estado de São Paulo. Os dados foram coletados entre os anos de 2004 e 2005, períodos nos quais pescadores artesanais, representantes de governo e organizações não governamentais foram entrevistados. Os resultados apontam a ausência de territorialidade local (dentro das comunidades), mas a existência de uma territorialidade implícita regional, entre as comunidades. Tanto a relação com as vizinhanças quanto à pesca realizada fora da comunidade contribuem na formação de uma percepção entre os pescadores da Almada de que o "mar é de todos". Entretanto, essa visão pública do mar não significa que este deve ser de livre acesso, sem regras. Ao contrário, muitos pescadores acreditam que é importante ter alguma forma de controle e esta deve ser negociada com os órgãos governamentais e representantes da classe de pescadores numa estrutura institucional horizontal, ou seja, na qual todos os grupos de interesses tenham poder de voto e decisão eqüitativamente.

Unitermos: territorialidade, análise de escala, pescadores artesanais, co-manejo, litoral norte do estado de São Paulo

\section{Abstract}

Is there artisanal fishing territoriality in the Ubatumirim Bay (Ubatuba, SP)? Scale issues in community relations. Scale issues are fundamental in the analysis of temporal and institutional dimensions of fishing territory. To understand actions and decisions at local and regional levels regarding fishing activity, we studied fishing communities at the Ubatumirim Bay, giving particular attention to the Almada community - north coast of the state of São Paulo. Data were collected between 2004 and 2005, a period in which artisanal fishers, officials and representatives of non-governmental organizations were interviewed. The results indicate the absence of territoriality at local level (within the community), but it exists implicitly at regional level (between communities). Both intercommunity relationships and fishing in areas outside the communities contributed to the building of a perception among fishers that "the sea belongs to everyone". However, such perception that the sea is public does not imply the kind of free access that is unbound by rules. On the contrary, a large 
number of fishers believe that is important to have some mechanisms of control, and this must be agreed upon by officials and grassroots organizations within a horizontal institutional arrangement, i.e., all the stakeholders must have equal rights to vote and to make decisions.

Key words: territoriality, co-management, scale issues, artisanal fishers, north coast of the state of São Paulo

\section{Introdução}

Os tópicos de interesse dos ecólogos são variados - de estudos de dinâmica de populações e co-evolução a mudanças ambientais - e a questão de escala está no cerne desta disciplina (Levin, 1992). Nas últimas décadas, a preocupação crescente com as mudanças ambientais globais colocou a questão de escala em mais evidência, pois tais mudanças envolvem ações locais com efeitos globais e trata diretamente das dimensões humanas (Sponsel et al., 1996; Gibson et al., 2000). O conceito de escala refere-se às dimensões espaciais, temporais, quantitativas e analíticas usadas pelos analistas para medir e estudar objetos e processos (Gibson et al., 2000).

Dentre os assuntos tratados na ecologia humana está a territorialidade pesqueira. A territorialidade na pesca vem sendo estudada intensivamente em várias partes do mundo, quer seja na pesca artesanal em pequena escala ou na pesca industrial costeira em escalas regional ou nacional (Acheson, 1981, 1987 e 1998; Ruddle, 1989, 1998a, 1998b; Begossi, 1995, 1999, 2001a e 2001b).

Territorialidade, aqui, entende-se como o ato de delimitar e defender uma área com recursos (Morse, 1980), excluindo-se alguns indivíduos do acesso aos mesmos. Por isso, a territorialidade apresenta certo custo para sua manutenção. Há locais onde a territorialidade conta com o apoio de um arranjo institucional regulando o uso e o acesso aos territórios delimitados, como ocorre com em algumas áreas costeiras do Japão e os respectivos recursos pesqueiros (Ruddle, 1989). Begossi (1998) aponta que os tipos de equipamentos utilizados, a densidade demográfica, as demandas do mercado e as pressões ambientais e governamentais são variáveis que levam a resultados diferentes em termos de territorialidade e da habilidade das organizações locais em definir as regras de acesso aos recursos e territórios. Christy (1987) argumenta que a territorialidade está presente mediante certas condições: (1) Aquisição relativamente fácil dos recursos e defesa dos direitos exclusivos sobre os mesmos; (2) Recursos sedentários, tais como ostras e moluscos; (3) Corpos de água fechados como lagos, represas e várzeas; e (4) Locais facilmente reconhecidos, como lagoas, praias e recifes de corais. Em alguns pontos da costa litorânea brasileira, observou-se que, não há regras para a pesca praticada com petrechos móveis (p.ex., linha e anzol); realizada em local com baixa densidade de pescadores profissionais e/ou amadores; e com alta diversidade de pescados e de áreas de pesca (Seixas e Begossi, 1998; Begossi, 2001a).

Uma das questões centrais com relação à demarcação espacial de territórios diz respeito à escala. Fazse fundamental a inclusão da noção de escala na análise do manejo pesqueiro, principalmente em se tratando do co-gerenciamento que envolve agentes de várias instâncias públicas, privadas e da sociedade civil (Begossi, 2001a). Em muitos casos, a exploração dos espaços marinhos ultrapassa os limites da comunidade ${ }^{1}$. Daí emerge a importância de se analisar a territorialidade numa perspectiva não só dentro dos limites espaciais

\footnotetext{
1 Comunidade aqui se refere a um grupo social, grupo de pessoas, que tem uma auto-identificação, laços de parentesco, e compartilham dos mesmos valores e crenças. Ainda na definição de Crane e Angrosino (1974) "um grupo de pessoas que tem organizações ou interesses comuns, habitam o mesmo local e estão sob as mesmas normas". Comunidade aqui também apresenta uma dimensão espacial, ou seja, as pessoas habitam e utilizam um espaço físico mais ou menos definido - espaço este considerado como parte da ou pertencente à comunidade. Em geral, a área terrestre considerada como pertencente à comunidade estende-se até a área da praia na baixa-mar (nível mínimo que a maré alcança em cada vazante). Já a área marinha "de uma comunidade" não apresenta delimitações claras, mas normalmente há alguns pontos de referência - como a ponta de uma encosta ou uma ilha - que as pessoas utilizam para traçar linhas imaginárias até onde o olhar (a partir da praia) alcança.
} 
de uma comunidade (intra-comunitária) mas também entre os limites espaciais de várias comunidades (inter-comunitária) e áreas maiores que podem abranger outros municípios ou estados (extra-comunitária) para se entender o uso e a ocupação do espaço marinho.

A territorialidade na pesca, a priori, refere-se a uma questão espacial. No entanto, a dinâmica do exercício da territorialidade revela suas dimensões espacial e temporal, conforme observou Begossi (2001a) em seu trabalho com os pescadores da Baía de Sepetiba, no estado do Rio de Janeiro. A autora observou a permanência dos pontos de pesca, por pelo menos, um intervalo de 10 a mais de 30 anos. Ademais, a territorialidade na pesca trata-se, muitas vezes, de um sistema de apropriação multiescalar. Os processos ecológicos e as mudanças ambientais, naturais ou antrópicas, são também multiescalares; ou seja, a ação ou decisão tomada em um nível pode afetar as ações em outros níveis (Gibson et al., 2000). Na gestão territorial dos recursos pesqueiros, por exemplo, a decisão tomada na instância estadual pode afetar as decisões e as ações municipais, que por sua vez, definem as atividades nas comunidades ou unidades domésticas (local).

O objetivo do presente estudo é verificar a existência ou ausência de territorialidade na pesca da comunidade da Almada, em Ubatuba (SP, Brasil) e a implicação disto para a gestão pesqueira. Para tanto, analisamos o uso e a ocupação dos espaços marinhos adjacentes à comunidade da Almada, a relação dos pescadores locais com os pescadores de comunidades vizinhas, e a experiência dos pescadores da Almada que trabalham ou trabalharam na "pesca embarcada" (i.e., pesca realizada em barcos semi-industriais e/ou industriais que ficam vários dias em alto mar).

\section{Material e Métodos}

\section{Método de Pesquisa}

A pesquisa de campo foi realizada em três etapas, quando conduzimos questionários e entrevistas junto a pescadores no litoral norte do município de Ubatuba, São Paulo: (1) de 13 a 17 de agosto de 2003, fizemos uma visita exploratória junto às comunidades de Cam- buri, Puruba, Picinguaba e Almada, para selecionarmos uma área específica; (2) de 3 a 17 de abril de 2004 e (3) de 15 a 19 de fevereiro de 2005, concentramos nossas pesquisas na comunidade de Almada. Como os métodos de pesquisa empregados foram somente diferentes formas de entrevistas, os nomes científicos dos pescados citados pelos pescadores baseiam-se do trabalho de Hanazaki e Begossi, (2000) que coletaram e identificaram taxonomicamente 66 tipos de pescado provenientes de desembarques pesqueiros na Almada.

Os métodos de pesquisa empregados na primeira viagem exploratória consistiram em entrevistas semiestruturadas e não-estruturadas (Bernard, 1994; Minayo et al. 2004) com lideranças comunitárias e pescadores experientes nas comunidades, com o Presidente da Colônia de Pescadores Z-10 de Ubatuba, e com pesquisadores e agentes de órgãos públicos que possuíam alguma atividade relacionada à pesca e à conservação: Secretário Municipal de Agricultura, Pesca e Abastecimento, Pesquisador do Instituto de Pesca - base Ubatuba, Pesquisador do Projeto TAMAR/IBAMA, Comando do Pelotão da Polícia Ambiental de Ubatuba e Coordenadora do Núcleo Picingüaba do Parque Estadual da Serra Mar. Nas segunda e terceira etapas de trabalhos de campo, realizamos entrevistas semi-estruturadas as quais foram gravadas com permissão prévia dos entrevistados e aplicamos questionários (Bernard, 1994) a 20 e 18 pescadores da Almada, respectivamente. Realizamos também um etno-mapeamento com nove pescadores que localizaram e identificaram os pontos e áreas de pesca utilizados pelos pescadores de Almada. Com o uso de um mapa regional (cortornos de uma carta topográfica), pedimos a três diferentes grupos de pescadores (grupos de dois ou três pescadores) para apontarem no mapa os locais onde costumavam pescar, quais os tipos de pescado capturavam em cada local, e quem mais pescava nessas áreas. Para cada grupo, utilizamos mais de um mapa (iguais para todos os grupos) e usamos lápis de diferentes cores para cada tipo de pescado para a identificação de pontos específicos e de áreas de pesca. Os pontos de pesca apontados pelos pescadores foram conferidos com os dados de GPS coletados por Begossi (2006) - quem foi acompanhada por um pescador experiente da comunidade da Almada. Os pontos de pesca apontados pelos pescado- 
res da presente pesquisa coincidiram com os coletados e georreferenciados por Begossi (2006). Os pontos da figura 1 são os resultados dessa sobreposição de informações.

\section{Área de estudo}

A comunidade da Ponta do Almada localiza-se no município de Ubatuba (SP), Brasil. Essa comunidade localiza-se a $35 \mathrm{~km}$ do centro de Ubatuba e tem como vizinhas as comunidades de Ubatumirim, Puruba e Picinguaba (Figura 1) e encontra-se de frente a duas praias: Engenho e Almada. Estas, por sua vez, encontram-se entre as Baías de Ubatumirim e Picinguaba (Figura 1).

A população nativa da Almada é formada por caiçaras. As populações caiçaras são caracterizadas predominantemente pela descendência de índios e portugueses (Adams, 2000); ocupam a costa litorânea brasileira e historicamente apresentam uma economia de subsistência, ou seja, dependem diretamente dos recursos aquáticos e terrestres para o sustento familiar.

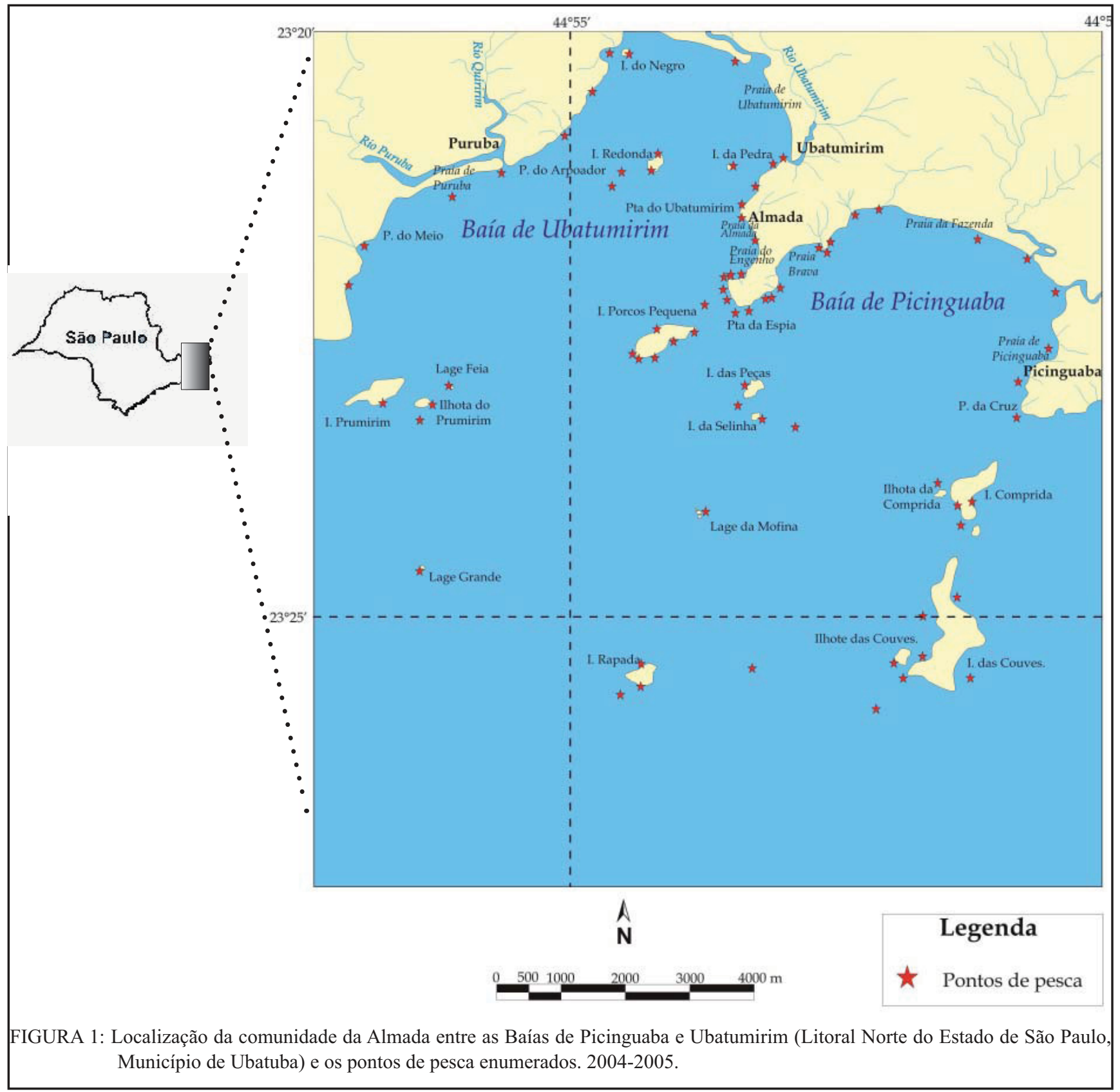

Revista Biotemas, 21 (1), março de 2008 
Além da população nativa, há alguns imigrantes, já antigos, que escolheram Almada como moradia, e hoje, fazem parte da comunidade. Esses imigrantes contribuíram de certa forma na organização da comunidade para a limpeza das praias e com programas de educação ambiental, e, portanto, podem ser vistos como 'agentes de mudança'. Estas ações não seriam possíveis, entretanto, sem a atuação da população local nesta empreitada, principalmente a participação dos jovens na organização, na política e na busca de alternativas econômicas para fixação dos mesmos na comunidade.

Os dados demográficos mostram que em 2003 havia cerca de 69 famílias e uma população de 242 pessoas (133 homens e 109 mulheres, sendo 44 crianças entre 1 a 14 anos) (Secretaria Municipal de Saúde de Ubatuba, 2003). Havia na comunidade também 15 casas de veraneio. Entre 1996-97, Hanazaki et al. (1996) contabilizaram 31 casas e 70 terrenos de propriedade de veranistas e uma população total de 125 habitantes; ou seja, a população local quase que dobrou em menos de uma década.

Em 2003, 20 crianças entre 7 e 14 anos (91\% das crianças nesta faixa etária) freqüentavam a escola e 170 pessoas acima de 15 anos (86\%) eram alfabetizados (Secretaria Municipal de Saúde de Ubatuba, 2003). Sessenta por cento das casas possuíam eletricidade (instalada ao redor de 1986) e apenas 1,5\% era abastecida por água da rede pública, sendo que quase $70 \%$ das casas dependiam de poço artesiano ou nascente (Secretaria Municipal de Saúde de Ubatuba, 2003). Não havia, na época da pesquisa de campo, telefone público ou privado, e o sinal para celular funcionavam muito precariamente. Também não havia mercados na comunidade. A estrada foi pavimentada em meados da década de 1990 e em 2004 havia ônibus três vezes ao dia da comunidade para o centro de Ubatuba (e viceversa).

A Sociedade dos Amigos do Bairro da Almada (SABA) organizava anualmente, desde 1993, no mês de julho o Festival do Camarão. Em 2003, foi comemorado o $10^{\circ}$ Festival e estimou-se um público de mais de 2.000 pessoas. Entre os eventos do festival estavam: apresentação de danças e de música, e comidas típicas à base de camarão. $\mathrm{O}$ dinheiro arrecadado revertia-se em melhorias da comunidade. Existia um grupo de voluntários (oito a dez pessoas) organizados pela SABA para limpar diariamente as praias. Os jovens da comunidade faziam manualmente cestos de lixo de bambu e cinzeiros que eram colocados ao longo da praia. Os membros da SABA e outros voluntários também trabalhavam na manutenção das vias de passagem de pedestres. Eles mantinham um estacionamento local e cobravam R $\$$ 4,00 a diária em 2003. O dinheiro arrecadado destinavase aos trabalhos da SABA. A AICAS representava uma organização não-governamental ambientalista (ONG) local criada por um imigrante junto com sete jovens da comunidade, para fazerem educação ambiental e trabalharem em parceria com a SABA. A AICAS foi formalizada para poder administrar o "Espaço Caiçara", um espaço contruído pela prefeitura na Praia do Engenho para servir de Museu e também sede da SABA.

\section{Pesca}

Em 2004-2005, a pesca ainda era uma importante fonte de subsistência para as famílias nativas da comunidade. Algumas famílias de pescadores ainda se dedicavam à pesca comercial de forma artesanal nas proximidades da Almada e comunidades vizinhas e ao cultivo de mariscos. Os pescadores da Almada utilizavam mais de 18 métodos de pesca (incluindo-se petrechos fixos ou móveis) (Tabela 1) e capturavam mais de 60 tipos de pescados, explorando mais de 70 pontos de pesca (Figura 1). Os pescadores da Almada exploravam os pontos de pesca com suas canoas a remo ou a motor ou com pequenos barcos a motor. Dentre os mais de 70 pontos de pesca, 16 eram considerados principais pelos pescadores (Tabela 2). Estes principais pontos distribuíam-se ao longo das Baías de Ubatumirim e Picinguaba, próximas às praias, às ilhas e lajes (afloramentos rochosos no mar). Havia ainda alguns pescadores que trabalhavam na pesca em alto-mar (pesca embarcada); estes trabalhavam para os peixeiros (atravessadores) de Ubatuba.

Os pescadores da Almada comentaram que capturavam uma variedade de pescados. Nas entrevistas, citaram o camarão branco (Litopenaeus schmitti), o camarão sete-barbas (Xiphopenaeus kroyeri), a tainha (Mugil spp.), a bicuda (Sphyraena guachancho), a so- 
roroca (Scomberomorus brasiliensis), o robalo (Centropomus spp.), entre tantas outras espécies capturadas. Algumas das espécies alvo para comercialização eram a tainha, o camarão branco e a lula (Loligo sp.). Durante nossa pesquisa, presenciamos, em 2004, uma pesca excepcional da lula, que segundo os pescadores foi a maior safra que eles já viram em suas vidas. Um atravessador que entrevistamos disse ter comprado mais de 6ton de lula só na comunidade de Almada. De fato, segundo dados do Instituto de Pesca (2007), a captura de lula no município de Ubatuba em 2004 foi de $297.196 \mathrm{~kg}$ - cerca de 15 vezes mais que a média de captura dos últimos seis anos (média de $19.191 \mathrm{~kg}$ - variando entre $5.431 \mathrm{~kg}$ em 1998 e $36.061 \mathrm{~kg}$ em 2003). A lula geralmente era capturada entre outubro a março.

TABELA 1: Uso de petrechos na comunidade de Almada, Ubatuba (SP). Abril (2004). N=20 pescadores

\begin{tabular}{l|c|c|c}
\hline $\begin{array}{c}\text { Tipos de apetre- } \\
\text { cho }\end{array}$ & $\begin{array}{c}\text { Em } \\
\text { uso }\end{array}$ & Introdução & Mobilidade \\
\hline Rede de Tainha & - & Antiga & Móvel \\
\hline Arrasto de praia & $\mathrm{X}$ & Antiga & Móvel \\
\hline Rede Feiticeira & $\mathrm{X}$ & Antiga & Fixo \\
\hline Espera de boiada & $\mathrm{X}$ & Antiga & Fixo \\
\hline Tresmalho & $\mathrm{X}$ & Antiga & Fixo \\
\hline $\begin{array}{l}\text { Tremalho para } \\
\text { Tróia }\end{array}$ & $\mathrm{X}$ & $\begin{array}{c}\text { Recente } \\
(25 \text { anos })\end{array}$ & Móvel \\
\hline $\begin{array}{l}\text { Arrasto de Cama- } \\
\text { rão }\end{array}$ & $\mathrm{X}$ & Antiga & Móvel \\
\hline Pesca de currico & $\mathrm{X}$ & Antiga & Móvel \\
\hline Pesca de espinhel & $\mathrm{X}$ & Antiga & Móvel \\
\hline $\begin{array}{l}\text { Pesca de linhada } \\
\text { ou linha de mão }\end{array}$ & $\mathrm{X}$ & Antiga & Móvel \\
\hline Caniço & $\mathrm{X}$ & Antiga & Móvel \\
\hline $\begin{array}{l}\text { Mergulho (Pesca } \\
\text { de Arpão) }\end{array}$ & $\mathrm{X}$ & $\begin{array}{c}\text { Recente } \\
(30 \text { anos })\end{array}$ & Móvel \\
\hline $\begin{array}{l}\text { Zangarelho } \\
\text { Rede de camarão }\end{array}$ & $\mathrm{X}$ & Antiga & Fixo \\
\hline Cerco & - & Antiga & Fixo \\
\hline $\begin{array}{l}\text { Arbitana (feiti- } \\
\text { ceira) }\end{array}$ & $\mathrm{X}$ & Antiga & Fixo \\
\hline $\begin{array}{l}\text { Marisqueira } \\
\text { Parelha }\end{array}$ & $\mathrm{X}$ & $\begin{array}{c}\text { Bem recente } \\
(6-7 \text { anos })\end{array}$ & Fixo \\
\hline & $\mathrm{X}$ & Antiga & Móvel \\
\hline Póvel
\end{tabular}

Revista Biotemas, 21 (1), março de 2008
Dentre os petrechos utilizados pelos pescadores da Almada, há equipamentos e técnicas introduzidos mais recentemente e outros mais antigos - que já eram utilizados na primeira metade do século XX (Tabela 1). Dos 18 petrechos listados na tabela 1, apenas dois - o cerco flutuante e a rede de tainha - estavam em desuso. O equipamento mais recente, a marisqueira, foi introduzida na segunda metade da década de 1990, para cultivar o mexilhão (Perna perna), localmente conhecido por marisco. A maioria dos equipamentos era móvel, entre os equipamentos fixos estão a rede de espera boiada, a rede de espera fundeada (rede de fundo) e a marisqueira, o que pode indicar uma das dificuldades em se estabelecer uma delimitação territorial.

TABELA 2: Pontos de pesca na comunidade da Almada, os mais citados entre os 72 reportados por 18 pescadores $(I D=$ número de identificação do ponto de pesca na Figura 1) (Fevereiro 2005).

\begin{tabular}{c|c}
\hline ID & Pontos de Pesca \\
\hline 1 & Lage da Espia \\
\hline 16 & Barra da Praia (Picinguaba) \\
\hline 36 & Ilha da Mofina (laje da Mofina) \\
\hline 37 & Ilha da Selinha \\
\hline 38 & Laje da Ilha das Peças \\
\hline 39 & Ilhas das Peças \\
\hline 41 & Escada (Ilha dos Porcos) \\
\hline 42 & Buraco da Andorinha (ilha dos Porcos) \\
\hline 43 & Calhéu do Anjo (Ilha dos Porcos) \\
\hline 52 & Lanço do Robalo \\
\hline 59 & Praia do Ubatumirim \\
\hline 64 & Barra da Puruba \\
\hline
\end{tabular}

Os pescadores de Almada pescavam camarão branco com rede de espera (flutuante) de malha " 6 " $\mathrm{cm}$ (entre nós opostos). A rede de espera (flutuante ou colocada ao fundo) era utilizada para capturar diversas espécies também. Utilizam a rede de cercar (maiores e com malha $12 \mathrm{~cm}$ ) ou a rede de "tróia" (menor e com malha $6 \mathrm{~cm}$ ) para a pesca da tainha, cara-pau (Caranx crysos) e sororoca entre outros peixes que formam cardumes. As redes de cercar e a de tróia eram utilizadas para cercar o cardume "no largo" (i.e., no mar) e lá mesmo eram recolhidas para as canoas. Havia também uma rede de arrasto de praia de malha $6 \mathrm{~cm}$, com ex- 
tensão aproximada de $300 \mathrm{~m}$ e profundidade de cerca de quatro metros. Há 10 anos os pescadores utilizavam o cerco, que pertencia a um dos pescadores mais velhos da comunidade. O zangarelho é um tipo de anzol especial para captura de lulas, na qual, participavam homens e mulheres, e até crianças. Pescavam de currico (linha solta flutuante e anzol, puxada por canoa), principalmente a bicuda e a sororoca; este método era utilizado também por algumas mulheres.

Em relação à maricultura (mitilicultura em particular), todos os moradores foram convidados a participar de um treinamento de cultivo de marisco (mexilhão Perna perna) oferecido pelo Instituto de Pesca (órgão do Estado de São Paulo), em meados da década de 1990, mas apenas três pescadores resolveram investir nesta atividade (três irmãos cada qual com sua família e os respectivos filhos). O cultivo do marisco consiste em 'plantar' 'sementes' de mexilhão produzidas em laboratório ou coletadas em costões rochosos, em sacos pendurados ao longo de um espinhel, conhecido por 'long line'. O 'plantio' era feito por volta de abril a junho e a colheita cerca de nove meses após - coincidindo com a alta estação de turismo. No início da produção de mariscos, os maricultores da Almada tiveram apoio e auxílio técnico do Instituto de Pesca. Apesar da boa produção (alguns dizem terem produzido aproximadamente 20 toneladas num só ano), os produtores não obtiveram o lucro esperado porque não conseguiram comercializar toda a produção. Em 2003, não chegaram a plantar mariscos pois não conseguiram coletar as sementes (informaram não ter sementes suficientes nos costões).

As marisqueiras localizavam-se em frente à ponta oeste da Praia do Engenho ao longo do costão (Figura 1), área conhecida localmente por "lanço do buraco" ou "lanço do robalo". Segundo alguns informantes, a localização foi definida em consenso após reunião com a comunidade. Em geral, não havia regra explícita entre os pescadores da Almada que definia o local de pesca.

Em 2005, havia cerca de 40 pescadores na comunidade, dos quais 16 (40\%) tinham na pesca sua principal fonte de sustento (Tabela 3); os demais pescadores $(60 \%)$ trabalhavam, em geral, em atividades voltadas ao turismo. A renda do turismo provinha de: aluguel de casa para turistas (temporadas); prestação de serviços como caseiros; comércio (restaurantes e bares); estacionamento na praia; aluguel de barco para pesca amadora; e aluguel de caiaque. Trabalhavam também na construção civil como pedreiros ou "embarcados" (i.e., pescadores empregados por donos de barcos). Até o final da década de 1970, a agricultura familiar (plantio de mandioca, feijão, abóbora, entre outros produtos) e a pesca eram as principais fontes de renda e de subsistência. Entretanto, a agricultura foi completamente abandonada após restrições legais de utilizar áreas de mata atlântica (políticas ambientais estaduais) a partir do final da década de 1980 .

Há mais de 40 anos, havia disputas internas (entre indivíduos da praia da Almada e indivíduos da Praia do Engenho) por causa da área de pesca da tainha. Esses indivíduos eram parentes entre si, ou seja, a dispusta dava-se entre familiares, mas que espacialmente residiam em áreas distintas (praia da Almada e praia do Engenho) da comunidade. Há 30-40 anos, a tainha chegava até a zona da praia (beira mar) e os pescadores preparavam redes de arrasto de praia para pescá-la. A pesca ocorria, em geral, entre as 20 horas e 3 horas da madrugada, nos meses entre junho e agosto, sendo julho o período de pico. De cada praia, saía, em geral, duas canoas com quatro a cinco pescadores para cercar o cardume; a pesca como um todo envolvia mais de 20 pescadores. Esses confrontos nunca foram violentos, mas havia "bate-boca" entre os dois grupos, conforme o relato dos próprios pescadores, e havia um respeito velado entre todos os envolvidos. Havia muito peixe, segundo esses pescadores, os quais estimam que podiam pescar até duas a três toneladas de tainha. Com o tempo, a quantidade de tainha foi reduzindo; os peixes não chegavam mais até a praia e as disputas se enfraqueceram. Atualmente, devido à área da Almada ter se tornado mais escassa em pescado, não há muitos pescadores "de fora" da comunidade, nem disputas internas. 
TABELA 3: Caracterização dos Pescadores da comunidade Almada. Abril (2004).

\begin{tabular}{c|c}
\hline Atributos & Dados Gerais \\
\hline Número de Pescadores & 37 \\
\hline $\begin{array}{c}\text { Idade dos Pescadores } \\
\text { (faixa etária) }\end{array}$ & 15 a 75 anos \\
\hline $\begin{array}{c}\text { Pescadores com experiência } \\
\text { em "pesca embarcada" }\end{array}$ & $\begin{array}{c}\text { Pescadores mais Idosos (16 } \\
\text { pescadores) }\end{array}$ \\
\cline { 2 - 2 } & $\begin{array}{c}\text { Pescadores mais Jovens } \\
\text { (16 pescadores) }\end{array}$ \\
\hline Pesca-Atividade Principal & 1 Família \\
\hline Pesca-Atividade Secundária & Demais Famílias \\
\hline Estabelecimentos & $\begin{array}{c}9 \text { estabelecimentos (82\% } \\
\text { do total de estabelecimen- } \\
\text { tos) }\end{array}$ \\
\hline
\end{tabular}

\section{As comunidades circunvizinhas}

\section{Puruba}

Esta comunidade era composta em 2003 por cerca de 20 famílias de caiçaras e 12 casas de veraneio. A construção da estrada BR-101 (Santos-Rio de Janeiro) em 1973 apesar de trazer benefícios na área de transporte, educação e saúde, também permitiu a invasão de turistas e pescadores de Ubatuba na comunidade. Ademais, propiciou a venda de terrenos locais "a preço de banana" na percepção de um nativo. Em 2004-2005, muitos jovens residiam na comunidade mas trabalhavam no centro de Ubatuba.

As famílias de pescadores não mais pescavam para a comercialização e apenas seis famílias pescavam para subsistência; o que também foi observado em 2003 por Lopes (2004). Quando capturavam muito pescado, os pescadores dividiam-no com os outros moradores e ficavam sem pescar por um tempo. A pesca era realizada principalmente no Rio Puruba, e não encontramos regra explícita que defina o local de pesca. Devido à redução da importância da pesca, poucos eram filiados à Colônia de Pescadores Z10.

Os pescadores pescavam com linha-anzol e rede "tresmalho" para cerco. A rede de cerco possuía malha de 8 e $10 \mathrm{~cm}$ entre nós opostos e um pano só; o cerco faz-se com canoa a remo. Na pesca de linha, a isca natural usada pelos nativos era camarão e lambari; a isca artificial para robalo foi introduzida por pescadores de fora. Algumas das espécies capturadas no rio eram: tainha e parati (Mugil curema) (no inverno), robalo, carapeva (Diapterus rhombeus), carapicu (Eucinostomus melanopterus) e bagre (diversas espécies de Ariidae).

No início da década de 2000, houve um aumento da pesca amadora (por turistas) no Puruba. O conflito entre pescadores locais e pescadores de fora (i.e., turistas e pescadores de Ubatuba) parece ser mais uma questão ambiental do que relacionada ao estoque pesqueiro. Segundo um morador "tem um problema sério com os pescadores que vem de fora; eles desmatam a margem do rio para lançar a linha do molinete e deixam muito lixo no lugar".

\section{Picinguaba}

A vila de Picinguaba foi tombada pelo CONDEPHAAT (Conselho de Defesa do Patrimônio Histórico, Artístico, Arqueológico e Turístico do Estado de São Paulo) e está dentro da área do Parque Estadual da Serra do Mar. A população da comunidade aumenta mais que o dobro na alta estação (verão). Em 2004, Picinguaba apresentava uma população de cerca de 623 pessoas, sendo que a maior parte $(60 \%)$ era de pessoas não nativas da comunidade, o que demonstra que o turismo era muito intenso, acarretando um crescimento desordenado. Em 2003, a população da comunidade era composta por 322 habitantes do sexo masculino e 301 mulheres, sendo que 222 encontravam-se na faixa etária entre 1 a 14 anos de idade (Secretaria Municipal de Saúde de Ubatuba, 2003). Havia 70 crianças entre 7 e 14 anos (66\%) que freqüentavam a escola na comunidade, sendo que 377 pessoas ( $86 \%$ ) eram alfabetizadas (Secretaria Municipal de Saúde de Ubatuba, 2003).

A pesca ocorria principalmente em alto mar, por exemplo, a pesca da corvina (Micropogonias furnieri) e do cação (diversas espécies de Elasmobranchii). $\mathrm{Ou}$ seja, os pescadores locais pescavam fora dos limites da comunidade. A frota de barcos semi-industrial era a segunda maior frota pesqueira do município de Ubatuba (a primeira era do centro de Ubatuba). 


\section{Camburi}

Em 2003, havia 54 famílias nativas (caiçaras), nove casas de moradores de fora (Secretaria Municipal de Saúde de Ubatuba, 2003), e cerca de 10 casas de veranistas. Em 1997-1996, contabilizava-se aproximadamente 70 casas e cerca de 300 pessoas (Hanazaki, 1997). Cada casa poder-se-ia considerar que era ocupada por uma família; portanto, houve um pequeno aumento no número de famílias de 1997 a 2003 . As famílias eram relativamente pequenas, com quatro pessoas em média (dois adultos e duas crianças) na comunidade (Hanazaki, 1997). Havia famílias que viviam nesta comunidade há mais de 250 anos. A comunidade era completamente isolada até 1973, quando foi construída a estrada que a liga até a BR 101 (foi construída pela empresa que abriu a rodovia Rio-Santos, hoje a rodovia BR-101). Os moradores viviam da agricultura e da pesca, até as roças serem proibidas com a encampação da comunidade pelo Parque Estadual da Serra do Mar por volta de 1985. Antes da estrada BR-101, o pescado era transportado por barco até Ubatuba para ser comercializado. Em 2004-2005, o turismo só era intenso nos feriados de Ano Novo e Carnaval. Dessa maneira, havia muitas famílias que não tinham renda fixa e só lucravam nestes feriados. Até no final da década de 1990, a pesca era rentável, mas ultimamente os pescadores disseram não ser mais.

Camburi possuía cerca de 36 pescadores com idades entre 14 e 76 anos, em 2003, e cerca de quatro pescadores locais pescavam embarcados em alto mar. Segundo os pescadores, faltava uma boa estrutura de comercialização, o que já os levou a perder capturas de lula (Loligo sp.) por falta de gelo e transporte no verão. A comercialização se dava através de um atravessador de Ubatuba que levava gelo e comprava o pescado dos pescadores da comunidade. Em 2003, havia quatro lanchas com motor na comunidade. Havia marisqueiras com apoio do Instituto de Pesca; e dois cercos flutuantes que eram colocados no verão. Estes cercos pertenciam a um morador de Camburi e a outro de Ubatumirim, e todos os auxiliares que trabalhavam neles eram da comunidade de Camburi. Os pescadores relataram que o governo colocou recifes artificiais em frente à praia de Camburi. Não encontramos regra ex- plícita que definia o local de pesca.

Os pescadores de Camburi utilizavam rede de espera (tresmalho), rede de fundo (feiticeira), picaré (rede de malha miúda) e alguns poucos usavam tarrafa. O mergulho e a pesca com molinete eram praticados, principalmente, por turistas. $\mathrm{O}$ arrasto de camarão setebarbas era praticado por barcos de fora. No passado, praticavam o arrasto de praia, mas, à época da coleta de dados, já não o faziam mais porque não havia peixe o suficiente, segundo os moradores. Entre as espécies capturadas, havia espada (Trichiurus lepturus), pirajica (Kyphosus sectatrix), sororoca e cavala (Scomberomorus cavalla). Em 2003, não se encontrava (ou capturava-se) mais a baqüara (Sarda sarda) (que chegava a $3 \mathrm{~kg}$ e é parente do bonito), o peixe-galo (Selene sp.) e o xaréu (Carax hippos). Os moradores relataram alguns conflitos entre pescadores locais $v s$. pescadores de mergulho (de fora) e pescadores locais $v s$. barcos de arrasto. Os barcos arrastavam também as redes de espera dos pescadores locais durante a noite, não propositalmente; porém, causando danos aos pescadores artesanais.

\section{Ubatumirim}

Em 2003, a população da praia de Ubatumirim e Cambucá (comunidade no interior, distante da praia) era composta de 412 habitantes, sendo 211 homens e 201 mulheres e distribuídos aproximadamente em 130 famílias (Secretaria Municipal de Saúde de Ubatuba, 2003). Havia 40 indivíduos entre 7 e 14 anos (77\%) que freqüentavam a escola, sendo que $85 \%$ (248 habitantes acima de 15 anos) eram alfabetizados (Secretaria Municipal de Saúde de Ubatuba, 2003). Como nas demais comunidades, $100 \%$ das casas dependiam de poços artesianos ou nascentes para o abastecimento de água e aproximadamente $95 \%$ das casas usavam fossa para o destino final do esgoto (Secretaria Municipal de Saúde de Ubatuba, 2003).

A pesca em Ubatumirim era predominantemente voltada para a subsistência, havia apenas um barco a motor. Há mais de 15 anos, havia um cerco flutuante nas proximidades da Ilha dos Porcos (redondezas da Almada); porém, em 2004, os equipamentos eram basi- 
camente móveis (pesca de linha e redes de espera). Os pescadores desta comunidade evitavam o uso de tróia, pois acreditavam que ela espanta o pescado; na pesca com tróia, batia-se na água com uma poita (pedra) para assustar o peixe que se enrosca na rede tornandose presas fáceis. Segundo alguns pescadores onde se fazia pesca com tróia, os peixes demoravam de 10 a 12 dias para reaparecer. A baía de Ubatumirim era conhecida como um importante e rico berçário de camarões e diversas espécies de peixes; portanto, era bastante freqüentada por vários pescadores da região, inclusive da comunidade da Almada. Segundo nos informaram, não havia conflitos violentos entre pescadores da Almada e Ubatumirim.

\section{As relações sociais e a territorialidade da pesca}

Seis pescadores (33\% dos entrevistados) da comunidade de Almada declararam espontaneamente que o mar é público, como nas palavras de um pescador "No mar todos podem pescar. Não tem área reservada. $\mathrm{Na}$ terra, tem dono". Os demais $77 \%$ também indicaram de forma mais implícita que não há territorialidade; provavelmente, há segredos quantos aos locais de pesca, mas isso não significa que haja restrições de acesso a esses locais. A ausência de territorialidade na fala dos entrevistados, com relação à restrição ao acesso dos pescadores "de fora" para os pontos de pesca da comunidade, deve-se a um conjunto de fatores, entre eles: (a) a grande variabilidade dos tipos de pescado e a redução do estoque dos principais recursos pesqueiros (p.ex., tainha, sardinha, cação e camarão), resultando numa pesca multi-específica (i.e., sem focar em uma espécie alvo); (b) a baixa dependência financeira da pesca artesanal, i.e., a maioria dos pescadores artesanais dedicam-se também às atividades turísticas; e (c) a dinâmica da pesca, com grande diversidade petrechos móveis e fixos e certa inovação tecnológica - mudanças nos métodos e petrechos utilizados ao longo do tempo (Tabela 2).

Outros fatores discutidos por Seixas e Begossi (1998) para explicar a falta de territorialidade na pesca artesanal em uma comunidade costeira no Brasil e que também são pertinentes a Almada incluem: alta imprevisibilidade temporal e espacial na distribuição dos recursos pesqueiros e fortes laços entre membros da mesma comunidade e de comunidades vizinhas baseados na reciprocidade. A relação inter-comunitária também foi observada na Almada, ou seja, ausência de conflito violento e a relação social relativamente amistosa com a maioria das comunidades vizinhas. Um segundo fator presente neste estudo de caso refere-se à experiência dos pescadores "embarcados" (da pesca semi-industrial) com uma noção de uso do espaço mais macroregional, sem demarcação territorial, ultrapassando os limites da comunidade, ou seja, com uma percepção de livre acesso.

\section{Relação social: Almada e as comuni- dades circunvizinhas}

Numa escala regional, observamos que pescadores locais e de comunidades circunvizinhas (Ubatumirim e Puruba, ao sul, e Picinguaba ao norte) pescavam nas áreas adjacentes a várias destas comunidades (Tabela 2). A Baía da Ubatumirim era a área mais visitada por pescadores da Almada, seguida de Puruba e Picinguaba: $100 \%, 89 \%$ e $89 \%$, respectivamente, dos 18 entrevistados na segunda etapa de campo. Quando perguntados sobre o uso do espaço marinho adjacente a Almada por pescadores de fora, dos 18 entrevistados, $67 \%, 61 \%$ e $44 \%$ responderam que ali pescavam respectivamente pescadores de Ubatumirim, Picinguaba e Puruba. Segundo alguns pescadores da Almada e Picinguaba sempre houve uma certa disputa entre as duas comunidades, incluindo a pesca. Ainda, de acordo com os pescadores, a rixa era mais acirrada entre as gerações mais antigas. Os jovens das duas comunidades, em 2004-2005, tinham uma relação mais amistosa. Em geral, os resultados indicam que a prática da pesca ultrapassa os limites da área marinha contígua a uma comunidade, conforme mostram os principais pontos de pesca da tabela 2 e figura 1 , o que provavelmente inibe a delimitação fixa e permanente de um território.

O padrão de distribuição espacial dos pontos de pesca e seu controle passam pelas relações sociais dentro e fora da comunidade e também pela construção da 
percepção espacial do uso do mar. Esta última traz implícita a idéia de a quem o mar pertence. No Japão, o sistema de apropriação marinha consiste de um jogo intrínseco que envolve regras de conduta na comunidade e comportamento interpessoal dos pescadores junto às instituições formais, que vai desde a associação comunitária (Fisheries Cooperative Association) até o Ministério da Agricultura, Floresta e Pesca (Rudd1e, 1992). No entanto, em situação sócio-institucional menos formal, onde se predominam as normas de convivência (conduta de agregação social) entre os pescadores artesanais, em geral, as instituições que regem os recursos naturais não são bem compreendidos. Isso representa uma séria "lacuna no conhecimento sociológico" que restringe severamente o planejamento e implementação de um sistema viável de apropriação marinha. Para este autor, entender os valores culturais, as normas de comportamento e conduta de cada sociedade são fundamentais para se entender o sistema de apropriação, neste caso de apropriação marinha ou "sea tenure" (Ruddle, 1992).

Em águas brasileiras, Begossi (2001a) argumenta que ambas a pesca artesanal marinha e a pesca ribeirinha compartilham a importância dos laços de parentesco na organização social. Estudando várias comunidades de pescadores, Begossi (2001a) também observou que os pontos de pesca usados pelos pescadores costeiros da Mata Atlântica comumente localizam-se próximos às comunidades, com exceção à pesca de embarcados como a que envolve pescadores da Almada e Picinguaba (ver seção a seguir). Considerando-se a escala de análise-espacial e temporal- observa-se diferentes padrões em relação aos pontos de pesca. No nível macro (regional), Begossi (2001a) observou que as localizações das áreas de pesca não mudaram nas comunidades em que as comparações temporais foram possíveis, tais como aquelas das Ilhas de Búzios e Baía de Sepetiba. A análise regional indica uma territorialidade implícita, ou seja, não há regras de uso e acesso declaradas, mas todos sabem dos limites das áreas de pesca de cada comunidade. No nível micro (local), os pontos de pesca podem pertencer a uma família de pescadores ou ser de uso exclusivo de pescadores artesanais de uma área particular conforme observou Begossi (2001a); no caso da
Almada, não observamos esse controle expresso das áreas de pesca dentro da comunidade.

\section{Experiência em alto-mar e a percepção espacial}

Na comunidade da Almada, parte dos pescadores tem trabalho assalariado em barcos de pesca semi-industriais e/ou industriais que ficam vários dias em alto mar, em outros municípios ou estados; esta pesca é chamada "pesca embarcada". Dos 40 pescadores locais, 32 (80\%) já pescaram "embarcados" em barcos de Santos (SP), Rio de Janeiro ou Santa Catarina (Tabela 3). Em 2005, 13 pescadores da Almada dedicavam-se integralmente à pesca embarcada. Estes pescadores possuem uma noção espacial que ultrapassa os limites da comunidade. Essa noção espacial se deve, principalmente à relação social entre os pescadores da Almada e das comunidades circunvizinhas e à experiência dos pescadores embarcados.

Segundo Begossi (2001a), no sudeste do Brasil, conflitos locais com arrastões (pesca industrial ou semi-industrial) são difíceis de serem intermediados e solucionados porque: (1) alguns pescadores locais estão engajados, pelo menos temporariamente, como trabalhadores embarcados na pesca de camarão sete-barbas e do camarão rosa, de sardinha, ou de cação; e (2) os donos de embarcações têm poder econômico e político. Dessa maneira, o envolvimento dos pescadores em pesqueiros de outros municípios ou estados, ou mesmo em alto-mar reforça o tipo de percepção espacial que eles constróem. Conforme define Ruddle (1989), o conceito de posse marinha inclui a percepção, a definição, a delimitação, a apropriação e a defesa pelos pescadores dos direitos sobre os pontos e áreas de pesca.

\section{Implicações da situação de "acesso li- vre" para o estabelecimento do zonea- mento costeiro através do co-manejo}

A pesca no espaço marinho adjacente à comunidade da Almada ocorre sem a definição de regras formais ou informais que regulam o uso e acesso ao local de pesca pelos pescadores - a exceção do 'direito do 
primeiro que chega ao ponto de pesca' (first comer's rights) e o respeito a este direito; não há regras que restrinjam o acesso de qualquer pescador ou a quantidade retirada de pescado nos pontos de pesca apontados neste estudo. Dessa forma, a experiência na atividade pesqueira fora da (extra) comunidade e o uso de pontos de pesca localizados em outras regiões (municípios, estados) provavelmente reforçam a percepção de que o mar é público. Diante desta percepção, seria possível implementar um plano de zoneamento costeiro na região?

Muitos autores apontam para a importância da criação de um arranjo institucional (conjunto de regras, que pode incluir ou não a criação de territórios) para a ordenação do uso do espaço para a pesca. Estes arranjos são partes centrais dos planos de manejo e de uso sustentável dos recursos marinhos, como propostos por Cardoso (2003) para um Zoneamento EcológicoEconômico Costeiro. Begossi (1995 e 2001a) em face aos conflitos entre pescadores locais e de fora, propôs a criação de Reservas Extrativistas Marinhas para as comunidades costeiras do Brasil, de maneira a minimizar tais conflitos. Christy (1987) aponta a presença de um sistema de apropriação territorial marinha encontrado há séculos em várias comunidades tradicionais ao redor do mundo -- Territorial User Rights in Fisheries (TURFs). Este sistema territorial envolve diferentes agentes situados em diferentes instâncias institucionais, como é o caso do co-manejo (Carlsson e Berkes, 2005), que representa um sistema multi-escalar e policêntrico.

McGinnis (1999) argumenta que, em muitos casos, um sistema multi-escalar e policêntrico é mais eficiente que uma grande unidade, como uma unidade governamental metropolitana ou simplesmente uma única camada de pequenas unidades. Para se compreender a estrutura, os processos e os resultados de um complexo sistema policêntrico de um sistema federal, precisa-se entender os níveis conceituais de tomadas de decisão que variam desde a escolha constitucional, através da escolha coletiva, até as escolhas operacionais (Ostrom et al., 1994).

A discussão sobre o sistema multi-escalar vem ocorrendo nas duas últimas décadas em relação aos vários tipos de políticas ambientais (Gibson et al., 2000).
Alguns ambientalistas visam engajar-se em questões políticas estritamente em nível local; outros em questões regionais e nacionais, e outros ainda dentro de regimes internacionais. No âmbito internacional, eles podem ganhar considerável atenção pública, mas chegam em acordos escritos que são pobremente cumpridos. Nos âmbitos local e regional, eles podem atingir um alto número de acordos, mas os acordos são cumpridos (Castro e McGrath 2003; Ruffino 2005). A análise da escala permite verificar se as decisões são tomadas em diferentes níveis (Castro 2004) e se há cautela com relação às generalizações das proposições feitas num nível da escala e aplicados em outro nível da mesma escala (Gibson et al., 2000). A verificação da presença de territorialidade faz-se pertinente para se compreender como se dá o gerenciamento dos recursos pesqueiros em seus vários níveis institucionais (comunidade, município e estado).

O discurso dos pescadores das comunidades da Baía de Ubatumirim e de Picinguaba revela um sistema local de livre acesso ao espaço marinho; entretanto, os resultados indicam que, na prática, há delimitações espaciais das áreas de pesca que "pertencem" a cada comunidade. A análise aponta para uma hipótese de que há um conflito tácito entre os pescadores das comunidades locais. Já entre os pescadores artesanais locais e os pescadores (semi-) industriais da pesca de arrasto de camarão há um conflito mais explícito pois os pescadores artesanais entendem que a pesca de arrasto, além de revolver o fundo do marinho onde muito organismos se alimentam, crescem e reproduzem, causa um impacto negativo sobre a ictiofauna acompanhante que é capturada e descartada (bycatch).

Em suma, apesar de não haver instituições locais que definam claramente uma territorialidade pesqueira, muitos pescadores acreditam que é importante ter alguma forma de controle das áreas de pesca local e regional e esta deve ser negociada com os órgãos governamentais e representantes da classe de pescadores numa estrutura institucional horizontal, ou seja, na qual todos os grupos de interessados tenham poder de voto e decisão eqüitativamente. Na região de Ubatuba, um arranjo que delimita áreas marinhas exclusivas para a pesca artesanal (exceto arrasto - que, mesmo em me- 
nor escala que a pesca semi-industrial, também revolve o fundo do mar) foi elaborado dentro da proposta de Zoneamento Ecológico-Econômico do Litoral Norte, como parte do Plano de Gerenciamento Costeiro do Estado de São Paulo (Seixas e Futemma, 2005). Esse Plano é uma tentativa de co-gerenciamento costeiro e é uma forma de institucionalizar a territorialidade da pesca na região. Para que esse co-gerenciamento ocorra de forma eqüitativa e o mais consensual possível, é necessário, entretanto, considerar as relações sociais e as percepções espaciais entre os pescadores.

\section{Agradecimentos}

Gostaríamos de agradecer a $\mathrm{Dr}^{\mathrm{a}}$ Alpina Begossi pelo incentivo e suporte, a FAPESP (Processo: 01/05263-2) e Centro Universitário SENAC/Área de Ciências Ambientais pelos apoios financeiros. Agradecemos também ao Salvador Carpi Jr. pela elaboração dos mapas. E, somos profundamente gratas às comunidades das Baías de Ubatumirim e Picinguaba, e em especial às famílias da comunidade da Almada e que nos receberam de maneira muito gentil e hospitaleira e aos pescadores, particularmente, pela colaboração e disposição para com esta pesquisa.

\section{Referências}

Acheson, J. 1981. Anthropology of fishing. Annual Review of Anthropology, 10: 275-315.

Acheson J. 1987. The lobsters fiefs revisited economic and ecological effects of territoriality in Maine lobster fishing. In: McCay, B. \& Acheson, J. (eds). The Questions of the Commons. University of Arizona Press, Tucson, USA, p.37-65.

Acheson, J. 1998. Lobster trap limits: A solution to a communal action problem. Human Organization, 57: 43-52.

Adams, C. 2000. Caiçaras na Mata Atlântica: Pesquisa científica versus planejamento e gestão ambiental. 1. ed. Editora Annablume - FAPESP, São Paulo, Brasil, 337pp.

Begossi, A. 1995. Fishing Spots and Sea Tenure: Incipient Forms of Local Management in Atlantic Forest Coastal Communities. Human Ecology, 23: 387-405.

Begossi, A. 1998. Property rights in different scales: Application for conservation in Brazil. Fisheries Research, 34: 269-278.

Begossi, A. 1999. Scale of interactions of Brazilian populations (caiçaras and caboclos) with resources and institutions. Human Ecology Review, 6: 1-7.

Begossi, A. 2001a. Cooperative and territorial resources: Brazi- lian artisanal fisheries. In: Burger J.; Ostrom E.; Norgaard R.; Policansky D. \& Goldstein B. D. (Ed.). Protecting the commons: A framework for resource management in the Americas. The Island Press, Washington, USA, p.109-130.

Begossi, A. 2001b. Mapping spots: Fishing areas of territories among islanders of the Atlantic Forest. Regional Environmental Change, 2: 1-12.

Begossi, A. 2006. Temporal stability in fishing spots: conservation and co-management in Brazilian artisanal coastal fisheries. Ecology and Society, 11(1): 5. [online] URL: <http://www.ecologyandsociety.org/vol11/iss1/art5/>.

Bernard, H. R. 1994. Research methods in anthropology: Qualitative and quantitative approaches. 2nd ed. SAGE Publications, Califórnia, USA, 585pp.

Cardoso, E. S. 2003. Territórios pesqueiros: Instrumentos de gestão. Ciência Hoje, 33 (196): 58-60.

Carlsson, L.; Berkes, F. 2005. Co-management: Concepts and methodological implications. Journal of Environmental Management, 75: 65-76.

Castro, F. 2004. Níveis de decisão e o manejo dos recursos pesqueiros. In: Begossi A. (Org.). Ecologia dos Pescadores da Mata Atlântica e da Amazônia. Hucitec/Nepam-Unicamp/NupaubUSP/Fapesp, São Paulo, Brasil, p. 255-284.

Castro, F.; McGrath, D. G. 2003. Moving toward sustainability in the local management of floodplain lakes fisheries in the Brazilian Amazon. Human Organization, 62: 123-133.

Christy, F. T. 1987. Territorial user rights in marine fisheries: Definitions and conditions. Food and Agriculture Organization (FAO) - Fisheries Technical Paper, 227: 1-10.

Crane, J. G.; Angrosino, M. V. 1974. Field projects in anthropology: A student handbook. General Learning Press. New Jersey, USA.

Gibson, C. C.; Ostrom, E.; Ahn, T. K. 2000. The concept of scale and the human dimensions of global change: A Survey. Ecological Economics, 32 (2): 217-239.

Hanazaki, N.; Leitão-Filho, H. F.; Begossi, A. 1996. Uso de recursos na Mata Atlântica e o caso da Ponta do Almada (Ubatuba, Brasil). Interciencia 21: 268-276.

Hanazaki, N.; Begossi, A. 2000. Fishing and niche dimension for food consumption of caiçaras from Ponta do Almada (Brazil). Human Ecology, 7:52-62.

Instituto de Pesca. 2007. Estatística pesqueira. Disponível em http://www.pesca.sp.gov.br/estatistica/index.php. Acesso em $22 \mathrm{de}$ outubro de 2007.

Levin, S. A. 1992. The problem of pattern and scale in ecology. Ecology, 73 (6): 1943-1967.

Lopes, P. F. M. 2004. Ecologia Caiçara: pesca e uso de recursos na comunidade da Praia de Puruba. Dissertação de Mestrado, Universidade de Campinas, Brasil, 130pp.

Minayo, M. C. S.; Deslandes S. F.; Neto, O. C.; Gomes, R. 2004. Pesquisa social: Teoria, método e criatividade. 23. ed. Editora Vozes, Petrópolis, Brasil, 80pp.

McGinnis, M. 1999. Polycentric governance and development: Readings from the workshop in political theory and policy analysis. University of Michigan Press, Ann Harbor, USA, 448pp. 
Morse, D. H. 1980. Behavioral mechanisms in ecology. Harvard University Press, Cambridge, USA, 383pp.

Ostrom, E.; Gardner, R.; Walker, J. 1994. Rules, games \& common-pool resources. The University of Michigan Press, Ann Harbor, USA, 369pp.

Ruddle, K. 1989. Solving the common property dilemma: Village fisheries rights in Japanese coastal waters. In: Berkes, F. (ed.). Common-property resources: Ecology and community-based sustainable development. Belhaven Press, London, UK, p.168184.

Ruddle, K. 1992. Administration and conflict management in Japanese coastal fisheries. FAO-UN, Rome, Italy.

Ruddle, K. 1998a. Traditional community-based coastal marine fisheries management in Vietnam. Ocean \& Coastal Management, 40: 1-22.

Ruddle, K. 1998b. The context of policy design for existing community-based fisheries management systems in the Pacific Islands. Ocean \& Coastal Management, 40: 105-126.
Ruffino, M. L. 2005. Gestão do uso dos recursos pesqueiros na Amazônia. PróVárzea/IBAMA/MMA, Manaus, Brasil. 120pp.

Secretaria Municipal de Saúde de Ubatuba. 2003. Banco de dados. Secretaria de Assistência à Saúde/COSAC/DATASUS. SIAB - Sistema de Informação de Atenção Básica, Ubatuba, Brasil, 1pp.

Seixas, C.; Begossi, A. 1998. Do fishers have territories? Use of fishing grounds at Aventureiro (Ilha Grande, Brazil). Crossing Boundaries - The Seventh Conference of IASCP, Vancouver, Canada. Disponível em $<$ http://www.indiana.edu/ iascp/iascp98.htm>.

Seixas, C.; Futemma, C. 2005. Co-management opportunities and challenges at the Ubatumirim Bay, Ubatuba, Brasil. Anais do XIX Meeting of the Society for Conservation Biology, Brasília, Brasil, p. 192.

Sponsel, L. E.; Headland, T. N.; Bailey, R. C. 1996. Tropical deforestation: The human dimension. Columbia University Press, New York, USA, 365pp. 